Elsevier required licence: (C) <2018>. This manuscript version is made available under the CC-BY-NCND 4.0 license http://creativecommons.org/licenses/by-nc-nd/4.0/

The definitive publisher version is available online at

[https://www.sciencedirect.com/science/article/pii/S0376738817328508?via\%3Dihub] 
1 Transport of small and neutral solutes through reverse osmosis membranes: Role of skin layer conformation of

\section{the polyamide film}

\author{
Revised manuscript submitted to
}

Journal of Membrane Science

December 2017

Takahiro Fujioka ${ }^{1, *}$, Brian E. O'Rourke ${ }^{2}$, Koji Michishio ${ }^{2}$, Yoshinori Kobayashi ${ }^{2}$,

Nagayasu Oshima ${ }^{2}$, Hitoshi Kodamatani ${ }^{3}$, Takuji Shintani ${ }^{4}$, Long D. Nghiem ${ }^{5}$

${ }^{1}$ Water and Environmental Engineering, Graduate School of Engineering,

Nagasaki University, 1-14 Bunkyo-machi, Nagasaki 852-8521, Japan

${ }^{2}$ National Metrology Institute of Japan, National Institute of Advanced Industrial Science and Technology, 1-1-1 Umezono, Tsukuba, Ibaraki 305-8568, Japan

${ }^{3}$ Division of Earth and Environmental Science, Graduate School of Science and Engineering, Kagoshima University, 1-21-35 Korimoto, Kagoshima 890-0065, Japan

${ }^{4}$ Division of Advanced Membrane Science and Technology, Graduate School of Science,

Technology and Innovation, Kobe University, 1-1 Rokkodai-cho, Kobe 657-8501, Japan

${ }^{5}$ Strategic Water Infrastructure Laboratory, School of Civil Mining and Environmental Engineering, The University of Wollongong, NSW 2522, Australia

* Corresponding author: Takahiro Fujioka, Email: tfujioka@nagasaki-u.ac.jp, Ph +81 0958192695 


\section{Abstract}

22 The polyamide skin layer of reverse osmosis (RO) membranes was characterised using advanced and complementary analytical techniques to investigate the mechanisms underlying the permeation of contaminants of emerging concern in potable water reuse $-N$ nitrosodimethylamine (NDMA) and $N$-nitrosomethylethylamine (NMEA). This study used five RO membrane samples with similar membrane properties. The five RO membrane samples spanned over a large range of water permeance $\left(0.9-5.8 \mathrm{~L} / \mathrm{m}^{2} \mathrm{hbar}\right)$ as well as permeation of NDMA (9-66\%) and NMEA (3-29\%). Despite such distinctthese differences among the five RO membranes, characterisations of the skin layer using positron annihilation lifetime spectroscopy, atomic force microscopy and field emission scanning electron microscopy revealed almost no variation difference - in their free-volume hole-radius $(0.270-0.275 \mathrm{~nm})$, effective surface area (198-212\%) and thickness (30-35 nm) of the skin layer. The results suggest that there could be other RO skin layer properties, such as the interconnectivity of the protuberances within the polyamide skin layer additional to the free-volume hole-size and thickness of the skin layer, which can also govern water and solute permeation. spectroscopy; potable reuse; reverse osmosis. 
$\mathrm{C}_{3} \mathrm{H}_{8} \mathrm{~N}_{2} \mathrm{O}$ ) are micropollutants of significant concern in potable water reuse since they are probable carcinogenic chemicals [1]. With a molecular weight of $74 \mathrm{~g} / \mathrm{mol}$, NDMA is the smallest in the $N$-nitrosamine group. NDMA and NMEA are neutral and hydrophilic compounds at environmental $\mathrm{pH}$ (i.e. $\mathrm{pH}$ 6-8). Although reverse osmosis (RO) membrane separation can achieve excellent rejection of a range of impurities in reclaimed water including salts, macro-organics, and many micropollutants, the rejection of NDMA, NMEA and several other $N$-nitrosamines is low and highly variable because of its small molecular size and lack of charge [2-5]. Thus, they are often detectable in RO permeate at concentrations higher than guideline or target values set by water authorities around the world. For example, California has established a notification level of $10 \mathrm{ng} / \mathrm{L}$ for NDMA and a public health goal of $3 \mathrm{ng} / \mathrm{L}$ [6]. Similarly, in Australia, the guideline value of NDMA in water intended for potable reuse has been also set at $10 \mathrm{ng} / \mathrm{L} \mathrm{[7].} \mathrm{The} \mathrm{low} \mathrm{and} \mathrm{highly} \mathrm{variable} \mathrm{separation} \mathrm{performance} \mathrm{of} \mathrm{RO}$ with respect to NDMA rejection necessitates post treatment by advanced oxidation (UV irradiation and $\mathrm{H}_{2} \mathrm{O}_{2}$ ) [8]. Recent research [9] suggests that NDMA rejection by RO membranes varies significantly amongst the many RO membranes available on the market. Thus, further insights which lead to better membrane selection and improvement of the separation performance of RO for $\mathrm{N}$-nitrosamine removal can directly contribute to the economic viability and public safety of potable water reuse.

Given the significant importance of low molecular weight micropollutants in potable reuse, numerous previous studies have been conducted to reveal the permeation mechanisms of micropollutants through RO membranes [10-13]. The significance of steric (size) interaction

Field Code Changed

Field Code Changed

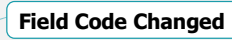

Field Code Changed between solutes and the free-volume holes within the RO membrane active skin layer has been 
clearly demonstrated from the viewpoint of solute properties. A strong correlation between molecular size (e.g. minimum molecular width or projected area) of uncharged solutes and their removals by RO has been established $[14,15]$. Nevertheless, mechanisms underlying the difference in NDMA permeation among RO membranes are still poorly understood from the perspective of membrane properties. This is mainly due to analytical limitations in characterising the membrane skin layer at sub-nanometre scale resolution.

The free-volume holes - holes in the membrane skin layer in polymeric matrix - are thought to play an important role in water and solute transport through the RO membrane. Nevertheless, findings to date remain inconclusive. The free-volume hole size can be determined by positron annihilation lifetime spectroscopy (PALS) [16]. Previous measurements of the free-volume hole-radius of commercial RO membranes [16-18] varied considerably from 0.20 and $0.29 \mathrm{~nm}$. Several previous studies [18-20] have demonstrated a strong correlation between solute permeation and free-volume hole-size. In contrast, no clear correlation between solute permeation and free-volume hole-size was reported by several other studies [17, 21, 22]. To date, there have been very few PALS studies on the characterisation of RO membranes due to the limited availability of slow positron beam based instruments.

The thickness of the skin layer has also been considered as an important property of an RO membrane governing water and solute transport. According to the solution-diffusion model [23-25], permeation of solutes and solution through RO membranes occurs via their penetration into the membrane material and diffusion through the RO membrane. The key role of the polymeric membrane thickness on solute permeation can also be supported by the finding that the thickness is inversely proportional to water permeance and there is a trade-off between water permeance and solute selectivity $[26,27]$. This mechanism is plausible, however, it is difficult to validate for commercial RO membranes. Recent RO membranes are designed with
Field Code Changed

\section{Field Code Changed}

Field Code Changed

Field Code Changed

Field Code Changed

Field Code Changed

Field Code Changed 
a rougher membrane surface that holds a higher surface area and a higher permeance [28-32].

As a result, they commonly have a so-called "ridge-and-valley" structure and hollow interior of crumpled nodules throughout the surface of the skin layer [29]. The entire thickness of the skin layer of commercial RO membranes is about $200-300 \mathrm{~nm}$ as reported by previous studies using transmission electron microscopy (TEM) [33-36]. The crumpled film forming the crumpled structure of the skin layer and the flat film comprising the interface between polyamide and polysulfone layers both have a thickness as low as $20 \mathrm{~nm}[31,37,38]$. Characterisation using a field emission - scanning electron microscope (FE-SEM) [37] allows for a quantification of each polyamide film. Nevertheless, due to the complex inner structure and rough surface morphology of the RO membrane skin layer and its variation among RO membranes, it is still difficult to identify the location of the most important polyamide films and quantify their thickness for comparison among different RO membranes.

A systematic evaluation of several RO membranes with similar chemical ingredients can potentially yield new insights into the role of the membrane skin layer on solute permeation. This study aims to identify key structure parameters that govern NDMA transport in the RO process by characterising the skin layer properties of five RO membranes that have similar chemical composition and skin layer structure. State-of-the-art analytical techniques including PALS, FE-SEM and atomic force microscopy (AFM) were used for the characterisation of the skin layer including free-volume hole-size, thickness and surface area, respectively.

\section{Materials and methods}

\subsection{Chemicals}

Analytical grade NDMA and $N$-nitrosomethylethylamine (NMEA) (Table 1) were purchased from Ultra Scientific (Kingstown, RI, USA). All stock solutions were prepared in methanol to
Field Code Changed

Field Code Changed

Field Code Changed

Field Code Changed

Field Code Changed 
112 Table 1 - Structure and properties of the selected $N$-nitrosamines.

\begin{tabular}{lcc}
\hline Compound & NDMA & NMEA \\
\hline Structure & 74.05 & 88.06 \\
Molecular formula & 0.04 & 0.4 \\
Molecular weight $[\mathrm{g} / \mathrm{mol}]$ & 3.5 & 3.4 \\
Log $D$ at $\mathrm{pH} 8^{\mathrm{a}}[-]$ & 0.20 & 0.22 \\
pKa at $\mathrm{pH} 8^{\mathrm{a}}[-]$ & $\mathrm{C}_{2} \mathrm{H}_{6} \mathrm{~N}_{2} \mathrm{O}$ & $\mathrm{C}_{3} \mathrm{H}_{8} \mathrm{~N}_{2} \mathrm{O}$ \\
Minimum projection area ${ }^{\mathrm{a}, \mathrm{b}}\left[\mathrm{nm}^{2}\right]$ & & 8
\end{tabular}

${ }^{\mathrm{a}}$ Chemicalize (http://www.chemicalize.org).

$114{ }^{\mathrm{b}}$ Minimum projection area is the area of the compound projected with the minimum plane of 115 its circular disk, based on the van der Waals radius.

\subsection{Membranes and membrane treatment system}

Two commercially available RO membranes - namely ESPA2 and ESPAB - and a prototype RO membrane were obtained as flat sheet samples from Hydranautics/Nitto (Osaka, Japan). The active skin layers of these membranes have similar chemical ingredients although the detailed information is proprietary. The ESPA2 membrane has been employed in many potable water reuse schemes [14], while the ESPAB membrane is designed for boron removal and has been widely used in the second pass of RO seawater desalination plants. In addition, samples of the ESPAB and Prototype membranes were also subjected to heat treatment to alter the physical properties. These heat-treated samples are designated as heated ESPAB and heated Prototype, respectively. Thus, in total, five different membrane samples were used in this investigation.
Formatted: Font color: Auto

Formatted: Font color: Auto Formatted: Font color: Auto Formatted: Font color: Auto Formatted: Font color: Auto Formatted: Font color: Auto Formatted: Font color: Auto Formatted: Font color: Auto

Field Code Changed 


\subsection{Experimental protocols}

\subsubsection{Heat treatment}

Heat treatment was conducted by heating the RO membrane coupons in $80^{\circ} \mathrm{C}$ ultrapure water solution. The RO membrane coupons were first rinsed with ultrapure water $(18.0 \mathrm{M} \Omega \mathrm{cm})$. Thereafter, each coupon was stored in a $200 \mathrm{~mL}$ beaker filled with ultrapure water, and the beakers were placed in a temperature-controlled water bath (SWB-11A, AS ONE, Osaka, Japan) that maintained the water temperature at $80{ }^{\circ} \mathrm{C}$. After $4 \mathrm{~h}$ of heat treatment, the membrane coupons were rinsed with ultrapure water and stored at $4{ }^{\circ} \mathrm{C}$ in the dark.

\subsubsection{RO filtration experiments}

The separation of NDMA and NMEA by each RO membrane was evaluated in ultrapure water using the bench-scale cross-flow RO system (Fig. S1). Filtration experiments were started with permeance evaluation in which RO membrane filtration experiments were conducted with ultrapure water at $2000 \mathrm{kPa}$ to measure the pure water permeance. Thereafter, NDMA and NMEA stock solution was added to obtain $200 \mathrm{ng} / \mathrm{L}$ of each compound in the feed solution. The membrane system was operated at a $20 \mathrm{~L} / \mathrm{m}^{2} \mathrm{~h}$ permeate flux and $20{ }^{\circ} \mathrm{C}$ feed temperature. Concentrations of NDMA and NMEA were determined by high-performance liquid chromatography-photochemical reaction-chemiluminescence as described in our previous studies $[40,41]$. The passage is defined as $R=100 \times C_{p} / C_{f}$, where $C_{p}$ and $C_{f}$ are solute concentration in the permeate and feed, respectively.

\subsection{Membrane characterisations}

\subsubsection{Surface chemistry}

Major functional groups of RO membranes was analysed using Fourier transform infrared spectroscopy (FTIR) spectrophotometer (Nicolet iS5, Thermo Fisher Scientific, Waltham, MA, USA) in attenuated total reflection (ATR) method. The RO membrane samples were freeze- 
151

$\tau_{o-P s}=0.5\left[1-\frac{r}{r+0.166}+\frac{1}{2 \pi} \sin \left(\frac{2 \pi r}{r+0.166}\right)\right]^{-1}$

dried for 24 hours using a freeze drier (FD-1000, Tokyo Rikakikai, Tokyo, Japan). The spectrum was obtained in the range of $400-4000 \mathrm{~cm}^{-1}$ at $1 \mathrm{~cm}^{-1}$ resolution.

\subsubsection{Positron annihilation lifetime spectroscopy (PALS)}

The free-volume hole-radius of each RO membrane was measured using PALS with a slow positron beam that is housed at the National Institute of Advanced Industrial Science and Technology (AIST) in Tsukuba, Japan. Details of PALS for the analysis of RO membranes are provided elsewhere [9]. The radius of free-volume hole $(r)$ of the skin layer in RO membranes was determined from the pick-off annihilation lifetime of ortho-positronium ( $\left.\tau_{\mathrm{o}-\mathrm{Ps}}\right)$ using the Tao-Eldrup model [42, 43]:

where $r(<1 \mathrm{~nm})$ is approximated as a spherical shape. Positron irradiation was carried out under vacuum $\left(\sim 10^{-5} \mathrm{~Pa}\right)$ and about $2 \times 10^{6}$ positron annihilation events were collected for the positron lifetime spectrum of each sample. Spectra were analysed using a non-linear leastsquares fitting program. Unless otherwise stated, the incident energy $\left(E_{i n}\right)$ was set at $1.0 \mathrm{keV}$, which corresponds to a mean implantation depth of $31 \mathrm{~nm}$ from the top (implantation depth range $=0-90 \mathrm{~nm}$ ) with a material density of $1.3 \mathrm{~g} / \mathrm{cm}^{3}$ (Fig. 1). This incident energy was selected according to previous studies $[18,19]$ that revealed the lowest free-volume hole-radius of polyamide RO at $1.0 \mathrm{keV}$. The dry material density of $\mathrm{RO}$ membranes $\left(1.3 \mathrm{~g} / \mathrm{cm}^{3}\right)$ was determined based on the data reported by Kolev and Freger [44].
Field Code Changed

Field Code Changed

Field Code Changed

Field Code Changed 


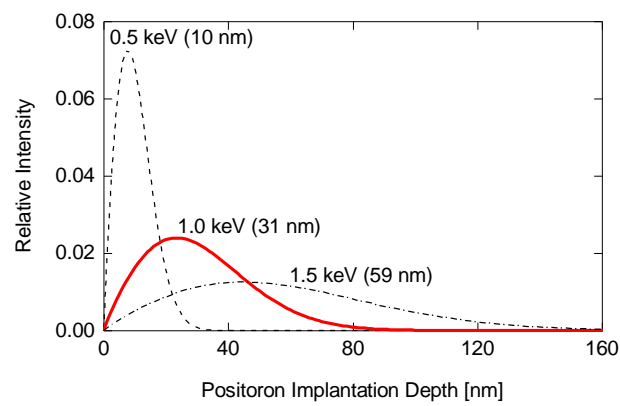

Fig. 1 - Distribution of positron implantation depth in a polyamide membrane sample with a material density of $1.3 \mathrm{~g} / \mathrm{cm}^{3}$ at a positron incident energy of $0.5,1.0$ or $1.5 \mathrm{keV}$. The mean implantation depth at each positron incident energy is shown in brackets.

\subsubsection{Atomic force microscopic analysis}

Membrane surface area was analysed using an atomic force microscope (AFM) (MFP-3D-SA, Asylum Research - Oxford Instruments Company, CA, USA). Membranes underwent sample pre-treatment steps involving the replacement of water in the membranes with tert-Butyl alcohol followed by freeze drying. Images were obtained in air using tapping mode with a silicate cantilever. The scanning area was $5 \mu \mathrm{m} \times 5 \mu \mathrm{m}$. The effective surface area of each membrane was calculated based on the data of three samples. Effective surface area here was defined as a ratio between the actual (measured) area and the sample area as described in the following formula:

Effecticve surface area $[\%]=\frac{\text { Actual area }\left[\mu^{2}\right]}{\text { Sample area }\left[\mu m^{2}\right]} \times 100$

\subsubsection{Field emission scanning electron microscopic analysis}

Cross-sectional images of the RO membrane skin layer were attained using a field emission scanning electron microscope (FE-SEM) instrument (S-4800, Hitachi, Japan) at $3 \mathrm{kV}$ accelerating voltage. Cross-sections of each membrane sample were prepared by freeze- 
fracturing wet membranes in liquid nitrogen followed by air drying. Thereafter, the target cross-sectional area was coated with conductive material prior to the analysis. The thickness of the skin layer of each RO membrane was calculated by determining the average of 5 different locations.

\section{Results and discussion}

\subsection{Solute permeation}

The five RO membrane samples examined in this study spanned over a large range of water permeance as well as solute passage with respect to both NDMA and NEMA (Fig. 2). Heat treatment was effective to reduce solute passage and water permeance. After heat treatment, NDMA passage through the ESPAB and the Prototype membranes decreased from 56 to $37 \%$ and from 18 to $9 \%$, respectively. The pure water permeance of these membrane also proportionally decreased as can be seen from Fig. 2. A strong linear correlation between solute passage with respect to both NDMA and NMEA and water permeance can be confirmed in Fig. 2. As noted in section 2.2, all five RO membrane samples were from the same manufacturer with similar chemical ingredients of the active skin layer. Thus, data from Fig. 2 allow for a systematic investigation of the role of the active skin layer in transport of small and neutral solutes as well as water across the membrane. 


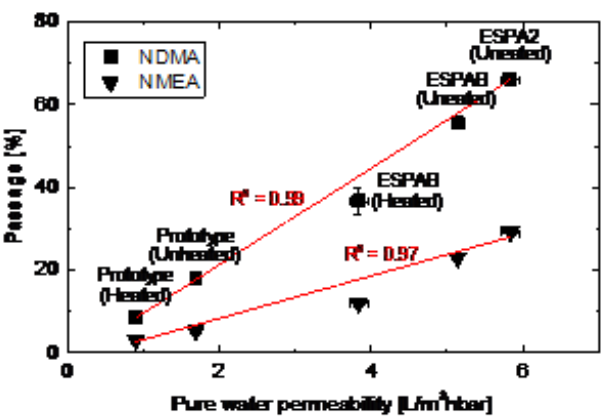

Fig. 2 - Correlation between the passage of NDMA and NMEA in pure water, and pure water permeance (feed temperature $=20.0 \pm 0.1^{\circ} \mathrm{C}$ and permeate flux $=20 \mathrm{~L} / \mathrm{m}^{2} \mathrm{~h}$ ). Error bars show the range of two replicate experiments.

\subsection{Characterisations of the RO skin layer}

210 3.2.1. Membrane chemistry

211 Variation in the top layer chemistry of RO membranes can be qualitatively evaluated by examining the FTIR spectra $[45,46]$. Notable peaks for fully aromatic polyamide were observed at 1668,1608 and $1539 \mathrm{~cm}^{-1}$ that correspond to $\mathrm{C}=\mathrm{O}$ and $\mathrm{C}-\mathrm{N}$ stretching and $\mathrm{C}-\mathrm{C}-\mathrm{N}$ deformation vibration (amide $\mathrm{I}$ ), $\mathrm{N}-\mathrm{H}$ deformation vibration and $\mathrm{C}=\mathrm{C}$ ring stretching vibration of aromatic amide, and $\mathrm{N}-\mathrm{H}$ in-place bending and $\mathrm{N}-\mathrm{C}$ stretching vibration of a - $\mathrm{CO}-\mathrm{NH}$ - group (amide II), respectively [47] (Fig. S2). Peaks at 1586, 1505, 1488 and $1245 \mathrm{~cm}^{-1}$ can be assignable to polysulfone. The ratio in peak intensity between $1668 \mathrm{~cm}^{-1}(\mathrm{C}=\mathrm{O}$ stretching of the amide group formed by the reaction between diamine and acid chloride) and $1245 \mathrm{~cm}^{-1}(\mathrm{C}$ O stretching of the polysulfone support) was $0.21,0.21$ and 0.17 for ESPA2, ESPAB and Prototype, respectively. This indicates that these RO membranes have a-similar chemical propertycomposition. In contrast, It is noted that heat treatment increased the peak intensity ratio from 0.21 to 0.30 and from 0.17 to 0.18 for ESPAB and Prototype membrane, respectively. The cause of the changes in the peak intensity for ESPAB after heat treatment remains unclear, but it will be in the scope of our future study. 


\subsubsection{Free-volume hole-radius}

The mean free-volume hole-radius of the selected RO membranes was determined at a mean implantation depth of $31 \mathrm{~nm}$ using $\tau_{o \text {-Ps }}$ values (pick-off annihilation lifetime of $o$-Ps) from PALS analysis (Table S3). The free-volume hole-radius of the three unheated RO membranes (i.e. ESPA2, ESPAB and Prototype) was almost identical, ranging from 0.270 to $0.275 \mathrm{~nm}$ (Fig. 3). Heat treatment did not show any discernible impact on the free-volume hole-radius. It is noteworthy that PALS analysis at other implantation depths (i.e. 10 and $59 \mathrm{~nm}$ ) of the ESPAB membrane did not show any significant variation in the free-volume hole-radius due to heat treatment (Fig. S4). It is noted that current PALS technique cannot confirm a small difference in free-volume hole-radius of RO membranes less than $0.01 \mathrm{~nm}$ due to the inherent errors in PALS and the inhomogeneity of the membrane samples. Thus, the free-volume hole-radius of all five membrane samples in Fig. $\mathbf{3}$ are considered to be similar.

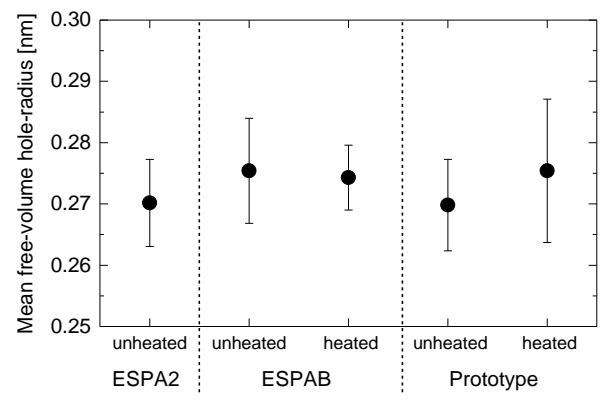

Fig. 3 - Free-volume hole-radius of the five RO membranes. The data here is the average and range of two replicates.

The cross-sectional areas of spherical free-volume holes with radii of 0.270 and $0.275 \mathrm{~nm}$ are 0.23 and $0.24 \mathrm{~nm}^{2}$, respectively. These values are comparable to the minimum projection area of NDMA $\left(0.20 \mathrm{~nm}^{2}\right)$ and NMEA $\left(0.22 \mathrm{~nm}^{2}\right)$ (Table 1). Because the passage of NDMA and NMEA varied with a difference of only $0.02 \mathrm{~nm}^{2}$ in the minimum projection area of the two 
molecules, a variation of $0.01 \mathrm{~nm}^{2}$ in free-volume hole-area among the five RO membranes may still be an important factor. However, there was no observable correlation between the measured free-volume hole-radius and the passage of NDMA and NMEA (Fig. S5). Given the similar free-volume hole-size of the five membrane samples, these results suggest that a factor other than the free-volume hole-size can also govern the permeation of NDMA and NMEA by these RO membranes.

\subsubsection{Effective surface area}

The effective membrane surface area was determined by taking into account the topography of the RO skin layer at the microscopic level (i.e. surface roughness) using AFM. Indeed, at the microscopic level, the effective membrane surface area can differ considerably from the surface area normally used to calculate the permeate flux [9]. It is noted that permeate flux considerably influences NDMA permeation [13]. Since the skin layer can play an important role in solute permeation through the RO membrane as proposed in literature [30, 38], it is important to take into account the effective membrane surface area when assessing solute permeation.

Despite the large variation in the visualized "ridge-and-valley" structure among the three different types of RO membranes (i.e. ESPA2, ESPAB and Prototype), their effective surface area was almost identical, ranging from 198 and 212\% (Fig. 4). In other words, the effective membrane surface area at the microscopic level is approximately two times the plain area. Likewise, heat treatment did not cause any discernible changes in the effective surface area. Results from Fig. 4 confirm that separation experiments in this study were also at the same permeate flux for a systematic comparison of solute permeation among all selected RO membranes. More importantly, the observation of the large variation in permeance (Fig. 2) and almost identical effective surface area (Fig. 4) among the RO membranes suggests that in this 

is noteworthy that the surface area determined by AFM does not necessarily represent the entire surface area. Surface areas through which feed solution can penetrate include the backside of bent protuberance and confined rumpled films with packed protuberances that cannot be measured by AFM [32]. Therefore, actual surface area taking account of all morphology is necessary to conclusively determine the role of surface area for water permeance.

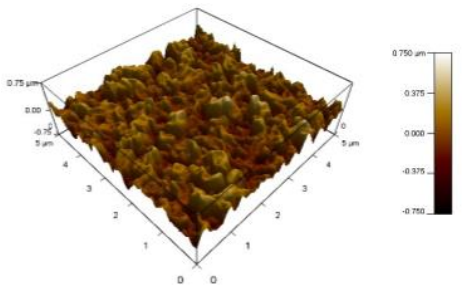

(a) ESPA2 (unheated) Area $=212 \pm 10 \%$

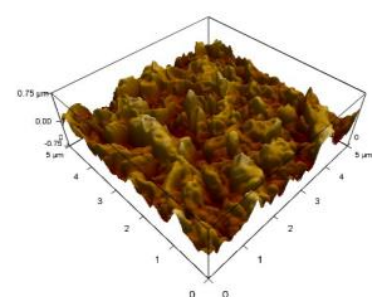

(b) ESPAB (unheated) Area $=204 \pm 6 \%$

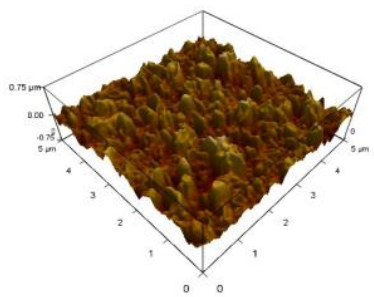

(d) Prototype (unheated) Area $=198 \pm 5 \%$

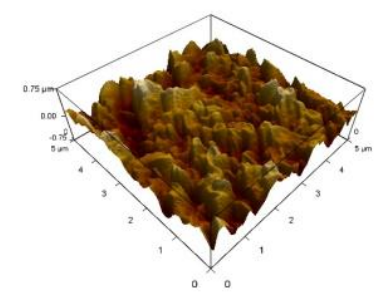

(c) ESPAB (heated)

Area $=202 \pm 3 \%$

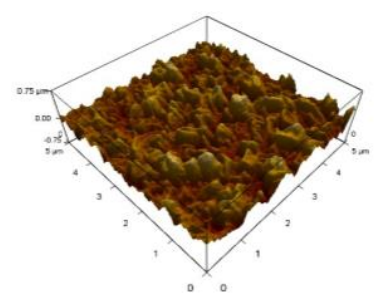

(e) Prototype (heated) Area $=205 \pm 3 \%$

Fig. 4 - AFM images of the five RO membranes. The surface area (and error) is determined from the average (and measurement variation) of three membrane coupons. 
The thickness of the skin layer of the selected RO membranes was evaluated using a crosssectional view obtained by FE-SEM. The FE-SEM analysis (Fig. 5) revealed a distinctive "ridge-and-valley" structure and a hollow interior of crumpled nodules throughout the skin layer of all RO membranes investigated in this study. These complex structures are similar to other commercial RO membranes recently reported in literature [36-38]. The estimated thickness of the skin layer was 300-400 nm for ESPA2 and ESPAB RO membranes and 200$300 \mathrm{~nm}$ for Prototype RO membranes. There was no apparent change in the skin layer thickness after heat treatment. The skin layer of these membranes comprised of two major polyamide films (A) a flat polyamide film that forms a film base at the interface with the polysulfone support layer and (B) a crumpled polyamide film that forms crumpled nodules with internal hollow structure (also called as protuberance) (Fig. 5). Ultrahigh resolution FE-SEM images in Fig. 5 show a similar thickness between the flat polyamide film and crumpled polyamide film. In addition, it appears that the crumpled polyamide film is almost always on top of the flat polyamide film. Using SEM, Yan et al. [37] also reported that the ESPA2 RO membrane has a through-bore that interconnects the cavity of the protuberance and open structure of the polysulfone support layer. The interconnections can also be found at the other four RO membranes used in this study. The majority of the protuberances did not appear to have interconnections. Although high water permeance of RO membranes (e.g. ESPA2) can be associated with the number of the interconnections, it was not possible to quantify the

Field Code Changed 

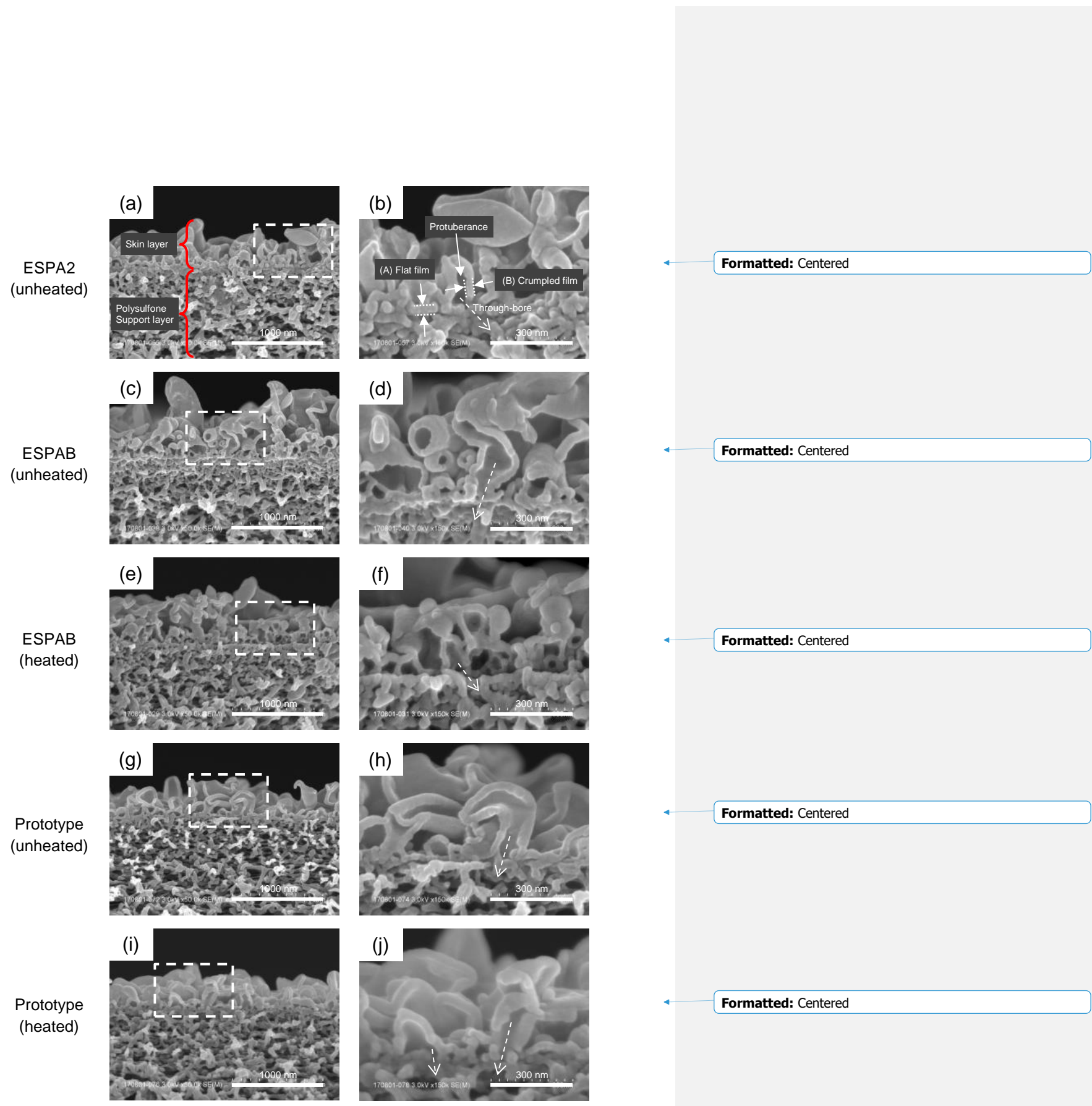

298 Fig. 5 - FE-SEM cross-sectional images of the five RO membranes: (a, c, e, g, i) skin \& polysulfone layers (scale $=1000 \mathrm{~nm}$ ) and $(b, \mathrm{~d}, \mathrm{f}, \mathrm{h}, \mathrm{j}$ ) areas enclosed with dash lines in the 300 skin \& polysulfone layers $($ scale $=300 \mathrm{~nm})$. 
Given the importance of the crumpled polyamide films on water and solute permeation $[30$, 37], the crumpled film thickness was measured for all the RO membranes. It is noted that the values were attained through two representative FE-SEM images; thus, there could be a variation in thickness throughout the RO membranes. The results revealed that unheated ESPA2, ESPAB and Prototype RO membranes had similar crumpled film thickness of 36, 29, and $34 \mathrm{~nm}$, respectively (Fig. 6). Results in Fig. 6 indicate that there was no discernible variation in thickness among the three RO membranes in this study. In addition, heat treatment did not appear to alter the crumpled film thickness. Indeed, differences in the crumpled film thickness between heated and unheated samples were within the measurement error margin (i.e. standard deviation of two samples of the same membrane). As a result, in this study, variation in water flux and the passage of NDMA and NMEA cannot be attributed to the measured crumpled film thickness (Fig. S7), suggesting that other skin layer properties such as conformation of the crumpled polyamide films could also govern their permeation.

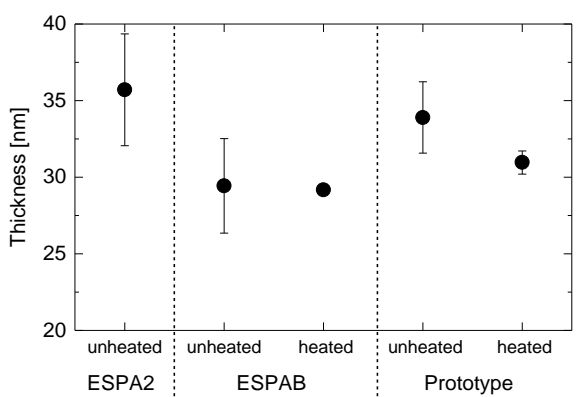

Fig. 6 - Thickness of the crumpled film of the five RO membranes. The thickness was determined based on two RO membrane coupons, each of which was measured at 5 locations (Table S6). 


\subsection{Discussions}

Comprehensive analysis of the skin layer of five RO membrane samples using PALS, FE-SEM and AFM revealed that there could be other RO skin layer properties besides the free-volume hole-radius and thickness of the crumpled film that can govern water and solute permeation. This is a significant finding in membrane transport, because the free-volume hole-radius and thickness of the crumpled film have often been considered the only membrane properties governing the membrane transport.

FE-SEM images obtained here identified that the free-volume hole-radius analysed by PALS was likely to result from the crumpled polyamide film. According to the distribution of positron implantation depth (Fig. 1), most positrons of PALS at a positron incident energy of $1 \mathrm{keV}$ were expected to have annihilated within the crumpled polyamide films that have the thickness of about $30 \mathrm{~nm}$. The flat polyamide film is mostly covered by several layers of the crumpled film and it is 300 to $400 \mathrm{~nm}$ away from the top ridge (Fig. 5). Thus, the flat polyamide film located at the interface with the polysulfone supporting layer is not accessible by positrons with $1 \mathrm{keV}$. Although the flat polyamide film beneath the crumpled films can be reached by increasing the positron incident energy (Fig. 1), increasing the incident energy also broadens out the positron implantation depth distribution, meaning that signals can be obtained from both the flat and crumpled films. As a result, thickness of the flat film that has far less surface area than the crumpled film cannot be accurately determined. If the flat polyamide film plays an important role in solute permeation, a sample preparation method that enables us to preferentially analyse the flat polyamide films should be developed.

In regard to the flat polyamide film, perhaps water permeance and separation performance of the selected RO membranes is related to the degree of the interconnections between the cavity of the protuberance and the open structure of the polysulfone support layer. In other words, RO 
membranes with less interconnections have less water permeance but high separation capability

The importance of hollow protuberance on the water permeance of RO membranes has been confirmed by Pacheco et al. [48] who evaluated 3D images of two commercial RO membranes using TEM tomography technique. The FE-SEM cross-sectional images in Fig. 5 revealed that not all of the protuberances have interconnections toward the polysulfone support layer. Protuberances without interconnections allow the solute and solvent (water) to permeate through two barriers - crumpled film and flat film, which could reduce water permeance but improve the separation performance. The projected area TEM technique previously reported by Pacheco et al. [36] and Yan et al. [37] has the potential to visualize the structure inside the ridges including the interconnections from its top view, but the correlation between the interconnections and separation performance has not yet been quantified.

There are some other limitations and challenges for the characterization of the RO skin layer with respect to PALS analysis. The analysis here was conducted under dry conditions, while wet RO membranes may have swelling effects [49], which can expand the polymer network and alter the water permeance and selectivity [50, 51]. In addition, the size distribution of freevolume holes may be more important than mean free-volume hole-radius, because the narrower passages connecting the major free-volume holes could actually determine solute permeations as suggested by Dražević et al. [52]. More accurate analysis with wet membrane samples and the determination of size distribution of free-volume holes requires a significant improvement in PALS method, thus, it is a scope of our future study.

In addition to the swelling effects, chemical properties of the internal skin layer could be a major contributor to a variation in diffusion coefficient and sorption coefficient of water and solutes, which ultimately leads to a variation in their water permeance and separation performance. Typically, increases in the degree of polyamide cross-linking can cause less water
Formatted: Font color: Auto

\section{Field Code Changed}

Field Code Changed 
and solutes to sorb onto the polymer due to restriction in swelling effects [53]. This could cause a decrease in both effective water and salt diffusion coefficients [54], leading to a decrease in water permeance but an increase in selectivity $\left(D_{w} / D_{s}\right)$ (trade-off theory) [26]. If that is the case, chemical properties of the skin layer such as cross-linking levels should be more important than the physical properties analysed in this study (i.e. free-volume hole-radius and thickness) to determine the major skin layer properties.

\section{Conclusions}

This study shows that RO membranes with distinct separation performance and water permeance can have similar crumpled film properties including free-volume hole-size and thickness. PALS, AFM and FE-SEM revealed that major crumpled polyamide film properties such as free-volume hole-size, effective surface area and thickness are almost identical among three different types of unheated RO (ESPA2, ESPAB and Prototype) and two heated RO (ESPAB and Prototype). The results suggest that there exist at least another RO skin layer property other than the free-volume hole-size and thickness that can also govern the transport of water and small and neutral solutes such as NDMA and NMEA that are of signifincant concern in potable water reuse. Such property is likely to be the protuberance conformation or interconnectivity of the protuberance within the membrane polyamide skin layer. In addition, FE-SEM data also reveal that current PALS technique may not be suitable for determining free-volume hole-radius of the flat polyamide film located at the interface between the polyamide skin and the polysulfone supporting layer beneath the crumpled polyamide films. Further advances in analytical technique that allows for the quantification of interconnections between the protuberances and the polysulfone support layer, the comprehensive characterisation of RO membranes by PALS (size distribution and wet conditions), and the 
evaluation of chemical properties of the polyamide films is necessary to fully decode the permeation mechanism of NDMA

\section{Acknowledgements}

This work was supported by KWEF Research Grant Program; JSPS KAKENHI Grant Number JP16H06104; and AIST Nanocharacterization Facility (ANCF) platform as a program of "Nanotechnology Platform" of the Ministry of Education, Culture, Sports, Science and Technology (MEXT), Japan. We also thank Hydranautics/Nitto for providing RO membrane samples for this investigation.

\section{References}

[1] US Environmental Protection Agency, Integrated Risk Information System (IRIS), Nnitrosodimethylamine. Office of Research and Development (ORD), National Center for Environmental Assessment (1987) www.epa.gov/iris/subst/0045.htm, in, 1987.

[2] M.J. Farré, K. Döderer, L. Hearn, Y. Poussade, J. Keller, W. Gernjak, Understanding the operational parameters affecting NDMA formation at Advanced Water Treatment Plants, J. Hazard. Mater., 185 (2011) 1575-1581.

[3] C. Bellona, J.E. Drewes, G. Oelker, J. Luna, G. Filteau, G. Amy, Comparing nanofiltration and reverse osmosis for drinking water augmentation, Journal AWWA, 100 (2008) 102-116.

[4] T. Fujioka, S.J. Khan, J.A. McDonald, A. Roux, Y. Poussade, J.E. Drewes, L.D. Nghiem, $N$-nitrosamine rejection by reverse osmosis membranes: A full-scale study, Water Res., 47 (2013) 6141-6148.

[5] M.H. Plumlee, M. López-Mesas, A. Heidlberger, K.P. Ishida, M. Reinhard, Nnitrosodimethylamine (NDMA) removal by reverse osmosis and UV treatment and analysis via LC-MS/MS, Water Res., 42 (2008) 347-355.

[6] CDPH, NDMA and other Nitrosamines - Drinking water issues, California Department of Public Health 2011.

[7] NRMMC, EPHC, AHMC, Australian guidelines for water recycling: Managing health and environmental risks (Phase 2): Augmentation of drinking water supplies, Environment Protection and Heritage Council, National Health and Medical Research Council, Natural Resource Management Ministerial Council, Canberra, 2008.

[8] H.L. Leverenz, G. Tchobanoglous, T. Asano, Direct potable reuse: A future imperative, Journal of Water Reuse and Desalination, 1 (2011) 2-10. 
[9] T. Fujioka, N. Oshima, R. Suzuki, W.E. Price, L.D. Nghiem, Probing the internal structure of reverse osmosis membranes by positron annihilation lifetime spectroscopy: Gaining more insight into the transport of water and small solutes, J. Membr. Sci., 486 (2015) 106-118.

[10] A.R.D. Verliefde, S.G.J. Heijman, E.R. Cornelissen, G.L. Amy, B. Van der Bruggen, J.C. van Dijk, Rejection of trace organic pollutants with high pressure membranes (NF/RO), Environ. Prog., 27 (2008) 180-188.

[11] C. Bellona, J.E. Drewes, P. Xu, G. Amy, Factors affecting the rejection of organic solutes during NF/RO treatment - A literature review, Water Res., 38 (2004) 2795-2809.

[12] L.D. Nghiem, P.J. Coleman, NF/RO filtration of the hydrophobic ionogenic compound triclosan: Transport mechanisms and the influence of membrane fouling, Sep. Purif. Technol., 62 (2008) 709-716.

[13] T. Fujioka, L.D. Nghiem, S.J. Khan, J.A. McDonald, Y. Poussade, J.E. Drewes, Effects of feed solution characteristics on the rejection of $N$-nitrosamines by reverse osmosis membranes, J. Membr. Sci., 409-410 (2012) 66-74.

[14] T. Fujioka, S.J. Khan, Y. Poussade, J.E. Drewes, L.D. Nghiem, $N$-nitrosamine removal by reverse osmosis for indirect potable water reuse - A critical review based on observations from laboratory-, pilot- and full-scale studies, Sep. Purif. Technol., 98 (2012) 503-515

[15] Y. Kiso, K. Muroshige, T. Oguchi, M. Hirose, T. Ohara, T. Shintani, Pore radius estimation based on organic solute molecular shape and effects of pressure on pore radius for a reverse osmosis membrane, J. Membr. Sci., 369 (2011) 290-298.

[16] S.H. Kim, S.-Y. Kwak, T. Suzuki, Positron annihilation spectroscopic evidence to demonstrate the flux-enhancement mechanism in morphology-controlled thin-filmcomposite (TFC) membrane, Environ. Sci. Technol., 39 (2005) 1764-1770.

[17] T. Fujioka, N. Oshima, R. Suzuki, S.J. Khan, A. Roux, Y. Poussade, J.E. Drewes, L.D. Nghiem, Rejection of small and uncharged chemicals of emerging concern by reverse osmosis membranes: The role of free volume space within the active skin layer, Sep. Purif. Technol., 116 (2013) 426-432.

[18] Z. Chen, K. Ito, H. Yanagishita, N. Oshima, R. Suzuki, Y. Kobayashi, Correlation study between free-volume holes and molecular separations of composite membranes for reverse osmosis processes by means of variable-energy positron annihilation techniques, J. Phys. Chem. C, 115 (2011) 18055-18060.

[19] K. Ito, Z. Chen, W. Zhou, N. Oshima, H. Yanagishita, R. Suzuki, Y. Kobayashi, Subnanoscopic holes in composite membranes for desalination elucidated by energytunable positron annihilation, Jpn. J. Poly. Sci. Technol., 69 (2012) 443-447.

[20] M. Henmi, Y. Fusaoka, H. Tomioka, M. Kurihara, High performance RO membranes for desalination and wastewater reclamation and their operation results, Water Sci. Technol., 62 (2010) 2134-2140. 
[21] T. Sasaki, H. Tomioka, K. Nakatsuji, Composite semipermeable membrane, production process thereof, and element, fluid separation equipment and treatment method for boron-containing water using the same, in: U.S. Patent (Ed.) United States Patent, Toray Industries, Inc., USA, 2010.

[22] T. Fujioka, N. Oshima, R. Suzuki, M. Higgins, W.E. Price, R.K. Henderson, L.D. Nghiem, Effect of heat treatment on fouling resistance and the rejection of small and neutral solutes by reverse osmosis membranes, Water Sci. Technol. Water Supply, 15 (2015) 510-516.

[23] J.G. Wijmans, R.W. Baker, The solution-diffusion model: a review, J. Membr. Sci., 107 (1995) 1-21.

[24] S. Bandini, L. Bruni, 2.04 - Transport Phenomena in Nanofiltration Membranes, in: E. Drioli, L. Giorno (Eds.) Comprehensive Membrane Science and Engineering, Elsevier, Oxford, 2010, pp. 67-89.

[25] J. Wang, D.S. Dlamini, A.K. Mishra, M.T.M. Pendergast, M.C.Y. Wong, B.B. Mamba, V. Freger, A.R.D. Verliefde, E.M.V. Hoek, A critical review of transport through osmotic membranes, J. Membr. Sci., 454 (2014) 516-537.

[26] G.M. Geise, H.B. Park, A.C. Sagle, B.D. Freeman, J.E. McGrath, Water permeability and water/salt selectivity tradeoff in polymers for desalination, J. Membr. Sci., 369 (2011) 130-138.

[27] H. Ju, A.C. Sagle, B.D. Freeman, J.I. Mardel, A.J. Hill, Characterization of sodium chloride and water transport in crosslinked poly(ethylene oxide) hydrogels, J. Membr. Sci., 358 (2010) 131-141.

[28] M. Hirose, H. Ito, Y. Kamiyama, Effect of skin layer surface structures on the flux behaviour of RO membranes, J. Membr. Sci., 121 (1996) 209-215.

[29] J.R. Werber, C.O. Osuji, M. Elimelech, Materials for next-generation desalination and water purification membranes, Nature Reviews: Materials, 1 (2016) 16018.

[30] S. Karan, Z. Jiang, A.G. Livingston, Sub-10 $\mathrm{nm}$ polyamide nanofilms with ultrafast solvent transport for molecular separation, Science, 348 (2015) 1347-1351.

[31] L. Lin, R. Lopez, G.Z. Ramon, O. Coronell, Investigating the void structure of the polyamide active layers of thin-film composite membranes, J. Membr. Sci., 497 (2016) 365-376.

[32] M.M. Kłosowski, C.M. McGilvery, Y. Li, P. Abellan, Q. Ramasse, J.T. Cabral, A.G. Livingston, A.E. Porter, Micro-to nano-scale characterisation of polyamide structures of the SW30HR RO membrane using advanced electron microscopy and stain tracers, J. Membr. Sci., 520 (2016) 465-476.

[33] A.K. Ghosh, B.-H. Jeong, X. Huang, E.M.V. Hoek, Impacts of reaction and curing conditions on polyamide composite reverse osmosis membrane properties, J. Membr. Sci., 311 (2008) 34-45. 
[34] C.Y. Tang, Y.-N. Kwon, J.O. Leckie, Characterization of humic acid fouled reverse osmosis and nanofiltration membranes by transmission electron microscopy and streaming potential measurements, Environ. Sci. Technol., 41 (2006) 942-949.

[35] V. Freger, Swelling and morphology of the skin layer of polyamide composite membranes: an atomic force microscopy study, Environ. Sci. Technol., 38 (2004) 3168 3175 .

[36] F.A. Pacheco, I. Pinnau, M. Reinhard, J.O. Leckie, Characterization of isolated polyamide thin films of RO and NF membranes using novel TEM techniques, J. Membr. Sci., 358 (2010) 51-59.

[37] H. Yan, X. Miao, J. Xu, G. Pan, Y. Zhang, Y. Shi, M. Guo, Y. Liu, The porous structure of the fully-aromatic polyamide film in reverse osmosis membranes, J. Membr. Sci., 475 (2015) 504-510.

[38] Y. Li, M.M. Kłosowski, C.M. McGilvery, A.E. Porter, A.G. Livingston, J.T. Cabral, Probing flow activity in polyamide layer of reverse osmosis membrane with nanoparticle tracers, J. Membr. Sci., 534 (2017) 9-17.

[39] B. Van der Bruggen, A. Verliefde, L. Braeken, E.R. Cornelissen, K. Moons, J.Q.J.C. Verberk, H.J.C. van Dijk, G. Amy, Assessment of a semi-quantitative method for estimation of the rejection of organic compounds in aqueous solution in nanofiltration, J. Chem. Technol. Biotechnol., 81 (2006) 1166-1176.

[40] T. Fujioka, H. Takeuchi, H. Tanaka, L.D. Nghiem, K.P. Ishida, H. Kodamatani, A rapid and reliable technique for $N$-nitrosodimethylamine analysis in reclaimed water by HPLC-photochemical reaction-chemiluminescence, Chemosphere, 161 (2016) 104111.

[41] H. Kodamatani, H. Yamasaki, T. Sakaguchi, S. Itoh, Y. Iwaya, M. Saga, K. Saito, R. Kanzaki, T. Tomiyasu, Rapid method for monitoring N-nitrosodimethylamine in drinking water at the $\mathrm{ng} / \mathrm{L}$ level without pre-concentration using high-performance liquid chromatography-chemiluminescence detection, J. Chromatogr. A, 1460 (2016) 202-206.

[42] M. Eldrup, D. Lightbody, J.N. Sherwood, The temperature dependence of positron lifetimes in solid pivalic acid, Chem. Phys., 63 (1981) 51-58.

[43] S.J. Tao, Positronium annihilation in molecular substances, J. Chem. Phys., 56 (1972) 5499-5510.

[44] V. Kolev, V. Freger, Hydration, porosity and water dynamics in the polyamide layer of reverse osmosis membranes: A molecular dynamics study, Polymer, 55 (2014) 14201426.

[45] M. Bass, V. Freger, Facile evaluation of coating thickness on membranes using ATRFTIR, J. Membr. Sci., 492 (2015) 348-354.

[46] E. Dražević, K. Košutić, V. Freger, Permeability and selectivity of reverse osmosis membranes: Correlation to swelling revisited, Water Res., 49 (2014) 444-452. 
[47] C.Y. Tang, Y.-N. Kwon, J.O. Leckie, Effect of membrane chemistry and coating layer on physiochemical properties of thin film composite polyamide $\mathrm{RO}$ and NF membranes: I. FTIR and XPS characterization of polyamide and coating layer chemistry, Desalination, 242 (2009) 149-167.

[48] F. Pacheco, R. Sougrat, M. Reinhard, J.O. Leckie, I. Pinnau, 3D visualization of the internal nanostructure of polyamide thin films in RO membranes, J. Membr. Sci., 501 (2016) 33-44.

[49] J. Lee, C.M. Doherty, A.J. Hill, S.E. Kentish, Water vapor sorption and free volume in the aromatic polyamide layer of reverse osmosis membranes, J. Membr. Sci., 425-426 (2013) 217-226.

[50] E.P. Chan, A.P. Young, J.-H. Lee, J.Y. Chung, C.M. Stafford, Swelling of ultrathin crosslinked polyamide water desalination membranes, J. Polym. Sci., Part B: Polym. Phys., 51 (2013) 385-391.

[51] Y.-H. Huang, W.-C. Chao, W.-S. Hung, Q.-F. An, K.-S. Chang, S.-H. Huang, K.-L. Tung, K.-R. Lee, J.-Y. Lai, Investigation of fine-structure of polyamide thin-film composite membrane under swelling effect by positron annihilation lifetime spectroscopy and molecular dynamics simulation, J. Membr. Sci., 417-418 (2012) 201209.

[52] E. Dražević, K. Košutić, V. Kolev, V. Freger, Does Hindered Transport Theory Apply to Desalination Membranes?, Environ. Sci. Technol., 48 (2014) 11471-11478.

[53] G.M. Geise, D.R. Paul, B.D. Freeman, Fundamental water and salt transport properties of polymeric materials, Prog. Polym. Sci., 39 (2014) 1-42.

[54] T.A. Jadwin, A.S. Hoffman, W.R. Vieth, Crosslinked poly(hydroxyethyl methacrylate) membranes for desalination by reverse osmosis, J. Appl. Polym. Sci., 14 (1970) 13391359. 